\title{
OS SINOS DOBRAM POR NÓS O mundo, o Brasil e as narrativas curriculares dos últimos tempos
}

\author{
Maria Inez Carvalho ${ }^{(*)}$ \\ Marcea Andrade Sales \\ Maria Roseli Gomes Brito de Sá
}

Com a decisão de começar este artigo com as conhecidas palavras que iniciam o romance Por quem os sinos dobram? (ERNEST HEMINGWAY, 2013) fomos atrás de precisar essa referência, e encontramos mais que uma referência; encontramos uma "cascata de atualizações" (LEVY, 2003). O cético Hemingway achou por bem começar aquele que viria a ser um dos mais famosos livros da literatura ocidental com citação redigida em 1764 pelo católico John Donne, isso em 1940. Três anos depois, o livro virou filme ganhador de Oscar e a pergunta-título, repetida incansavelmente, se torna até nome de música com Raul Seixas nos anos 1970. (DIAS, 2016).

E continuamos, pelo século XXI, a perguntar: Por quem os sinos dobram?, e a respirar fundo sempre que revisitamos a atual centenária escrita de John Donne:

Nenhum homem é uma ilha isolada; cada homem é uma partícula do continente, uma parte da terra; se um torrão é arrastado para o mar, a Europa fica diminuída, como se fosse um promontório, como se fosse a casa dos teus amigos ou a tua própria; a morte de qualquer homem diminui-me, porque sou parte do gênero humano. E por isso não perguntes por quem os sinos dobram; eles dobram por ti. (DONNE, citado por HEMINGWAY, 2013, posição: 54).

Se nenhum homem é uma ilha, por extensão nenhuma Escola também o é. Então, resta-nos perguntar quais os sinos que dobram, hoje, por ela?

\section{O MUNDO E A ESCOLA}

Em 09 de novembro de 1989 os sinos dobraram e o réquiem foi para o fim do socialismo, mais precisamente o fim da guerra fria. $\mathrm{O}$ dia em que milhares foram às ruas para derrubar o Muro de Berlim, construído 28 anos antes. E sem a guerra fria, vivemos a década de 1990, acreditando na

\footnotetext{
${ }^{(*)}$ Maria Inez Carvalho. Professora associada IV da Faculdade de Educação da Universidade Federal da Bahia (UFBA). E-mail: miscarvalho@yahoo.com.br.

Marcea Andrade Sales. Doutora em Geografia. Universidade Estadual da Bahia (UNEB). E-mail: msales@uneb.br.

Maria Roseli G. Brito de Sá. Doutora em Educação. Professora Associada III Faculdade de Educação - UFBA. E-mail: roselisa@ufba.br.
} 
derrocada da díade direita-esquerda. Um livro seminal para essa discussão é Direita e Esquerda razões e significados de uma distinção política, de Norberto Bobbio (1995). No prefácio à primeira edição, como a comprovar que à época muito se defendia a defenestração dos conceitos de direita e esquerda, traz uma citação de Revelli:

Estranho destino tiveram, neste último lapso de século, os conceitos antitéticos e complementares, de direita e esquerda. Dois conceitos que, nos limites de pouco mais de um decênio, deixaram de ser o critério constitutivo e fundante do discurso político, e não só do ineliminável antagonismo por ele proposto - critério não apenas descritivo da realidade, mas também prescritivo do agir - e se tornaram sucata ideológica para ser exibida no grande museu de cera ao lado das velhas ilusões de palingenesia e das roupas abandonadas do militante político (REVELLI citado por BOBBIO, 1995, p. 27).

E pelas 129 páginas da obra, o autor elabora uma exaustiva discussão - que não é objetivo nosso detalhar, mas que recomendamos fortemente a leitura - na qual, através de capítulos com títulos sugestivos como A Díade Sobrevive, Liberdade e autoridade, Igualdade e Desigualdade, defende a igualdade como o valor que refundará a "famigerada" díade ${ }^{1}$ direita-esquerda. Declara como objetivo da obra "dar conta de um debate que continua vivo não obstante os lúgubres e recorrentes dobres fúnebres (rintocchi de morte)” (BOBBIO, 1995, p. 126).

De fato, tempo houve, e não muito distante, em que o uso dos termos esquerda e direita soava muito anacrônico. Entretanto, mais recentemente, os dobres fúnebres cessaram, e a díade, mais "famigerada" do que nunca, ressurge! As oposições se reafirmam em um cenário de grande visibilidade e, curiosamente, o fato que emergia na década de 1990 como o fator que tornou ultrapassada a distinção esquerda/direita - o comunismo ou o seu desmoronamento - é reavivado, anacronicamente, - não há concretamente um revival dos Estados Comunistas - como peça de conceituação da díade. Revival de certo modo surpreendente que nos faz indagar: se vivo estivesse, como Bobbio avaliaria essa nova feição do mundo? E como, nesse período de uma geração, que nos separa do dia em que "o muro foi derrubado", a escola ouviu e executou esses dobres, como respondeu à indagação: Por quem os sinos dobram?

Pensar a escola brasileira, nesse cenário, hoje, 2016, pode ser assim metaforizado. Os sinos que anunciavam a morte da díade direita/esquerda, por uma série diversa de fatores foi ouvido por algum tempo, até que, difícil precisar se lentamente ou não, cessa. E o som dos sinos é substituído por gritos. Muitos gritos que anunciam, de forma denuncista, que a direita e esquerda nunca

\footnotetext{
${ }^{1}$ O termo díade é tratado aqui a partir do que nos informa Abbagnano (1982, p. 269): "Segundo os pitagóricos, é "o princípio da diversidade e da desigualdade, de tudo o que é divisível e mutável e ora está de um modo, ora de outro" (PORFÍRIO, Vita Pith., 52). Contrapõe-se à mônada, que é o princípio da unidade, do ser idêntico e igual".
} 
estiveram mortas e que, sorrateiramente, a "esquerda" teria invadido a escola brasileira. Então, não é a refundação da díade, idealizada por Bobbio, pelo valor - igualdade -, mas um revival dicotômico de reacender um comunismo e afins, que já não existe mais concretamente; e que deságua, por exemplo, na proposta da Escola Sem Partido. ${ }^{2}$

$\mathrm{O}$ réquiem à díade esquerda-direita nos anos da derrocada do socialismo real veio seguido de outro dobrar de sinos: os sons que anunciavam o Fim da história - o livro que marcou essa discussão foi O Fim da História e o Último Homem de Francis Fukuyama (1992). A tese do fim da história se reaviva com a queda do socialismo real quando o prenúncio de mundo único no pósguerra fria deu munição para a defesa da visão de que a democracia capitalista liberal seria o estádio final do processo histórico (FUKUYAMA, 1992). Tese que foi refutada em duas antagônicas linhas não homogêneas. Aquelas que a negavam totalmente, em nome do dinamismo histórico e aquelas que a ressignificam, aceitando, não o fim da história como um ápice das civilizações, mas o fim de uma história, a história entendida como progressão linear.

É consensual que a queda do Socialismo Real abalou, fortemente, as crenças - já, na época, em processo crescente e não recente de questionamento - nas teorias sociais críticas, principalmente no aspecto da busca transcendental de um paraíso (progressão linear). É conhecido o desabafo de Neil Smith, citado em forma de epígrafe por David Harvey: "O iluminismo está morto, o marxismo está morto, o movimento da classe trabalhadora está morto... E o autor também não se sente muito bem.” (SMITH citado por HARVEY, 1993, p. 185).

É dessa década a emergência na literatura pedagógica das chamadas teorias pós-críticas como uma resposta aos dilemas postos pelo contexto e uma ressignificação das ideias antes propostas.

Traçar esse cenário geo-histórico não estaria completo sem outra metáfora: os réquiens anunciando o fim da história e a defenestração da díade direita-esquerda são dobrados pelos "novos sinos" da tecnologia. Essa nova ordem mundial foi alicerçada pelo advento das então chamadas Novas Tecnologias. O mundo depois da Internet não seria o mesmo. Velocidade não era a mesma coisa. Entre os catastrofistas e os encantados a vida continuava diferente. Em meio às díspares posições - de um lado o luto pela impossibilidade dos sonhos de uma sociedade melhor e mais justa causada pelas novas tecnologias (máquinas que estavam tornando realidade concreta o sombrio mundo orwelliano do romance 1984), e de outro os festejos pelas possibilidades de democratização

\footnotetext{
${ }^{2}$ Projeto de lei de cunho conservador que tramita no senado brasileiro. Os autores da proposta julgam que transversa na escola brasileira uma profunda doutrinação de esquerda e pretendem coibi-la. Para conhecer mais: <http://www.programaescolasempartido.org/>. Acesso: 29 set. 2016.
} 
advindas com as Novas Tecnologias - um mundo acontecia, como desde sempre, complexamente. Era o tempo da tão glamourizada Globalização.

Para demonstrar que esse mundo "se identifica com a estética da saturação, do excesso, da máxima concentração de informação em um mínimo espaço/tempo" (CARVALHO e SARDELICH, 2000, p. 110), apossamo-nos de uma lista criada por Carvalho (2001, p. 19) a partir de ideias contidas no primeiro capítulo do livro A sociedade em Rede de Castells (1999):

Nesse momento, de intensas mudanças, as [escolas] continuavam se espalhando pelo mundo, um mundo no qual: o muro de Berlim tinha caído, uma revolução tecnológica remodelava as bases materiais da sociedade, a guerra fria terminava, as economias se interdependiam globalmente, declinava o movimento operário, o patriarcalismo era atacado, o e-mail começava a ligar qualquer parte do mundo, o capitalismo se reestruturava, o Pacífico Asiático ascendia como região promissora mundialmente, acentuavam-se as desigualdades mundiais e regionais, além de redes interativas de comunicação, biogenética, valorização das culturas locais, aumento da violência, redefinição das relações sociais fundamentais, consciência ambiental, crise do estado-nação, reagrupamento em grupos de identidades primárias, fundamentalismo religioso, fragmentação social, impotência da sociedade frente ao seu destino, enquanto a Internet começava a lentamente se espalhar pelo mundo...

Quaisquer que sejam as referências que nos impulsionam a construir uma narrativa sobre esse novo mundo globalizado, esse é um período com forte dimensão não conservadora. Na escola, tanto as posições defensoras de um status-quo capitalista, naquele momento, fortemente neoliberais; quanto as mais críticas à Nova Ordem Mundial que se impunha, têm a força do novo. Não há defesa, pelo menos majoritária, de currículos tradicionais, ou seja, em um pólo as mudanças curriculares neoliberais, de certa maneira, impostas pelo Banco Mundial; de outro a tecnologia vista como possível fator estruturante de novos currículos para educações plurais. É nesse quadro que se instaura a Lei de Diretrizes e Bases da Educação Nacional no Brasil em 1996. Passados 20 anos, é importante a indagação: como/onde situá-la entre esses dois pólos de um rico continuum?

Assim, adentramos em um novo século em que se ouviam os sinos dobrando pela "morte" de certas imposições. Já era possível, com certa tranquilidade, se usar a primeira pessoa do singular em textos acadêmicos em um claro abandono da neutralidade como princípio; escrevia-se a várias mãos (parecia fadado a prosperar iniciativas como $\mathrm{NTC}^{3}$ em que os autores se diluíam no coletivo); contávamos nossas histórias sem precisar nos esconder em anonimatos garantidores de pretensas imparcialidades; as experiências, em suas singularidades, ganhavam status científicos e muito mais.

\footnotetext{
${ }^{3}$ Núcleo de Pesquisa da Faculdade de Comunicação da (ECA/USP), que publicava livros de autoria coletiva como, por exemplo, Pensar pulsar. Para consulta, segue a referência: COLETIVO NTC. Pensar pulsar - cultura comunicacional, tecnológica, velocidade. São Paulo: Edições NTC, 1996.
} 
Porém, em 11 de setembro de 2011, novos dobres fúnebres (rintocchi de morte), dessa vez para a liberdade. Invés do fim da história, vivemos uma história sem fim. Após o ataque às Torres gêmeas, em Nova York, novos e velhos "inimigos" emergem, em sombrio cenário de muita criação imaginária e exageros. Gradativamente, o velho retoma; a dimensão conservadora se expande.

Ironicamente são as Novas (?) Tecnologias com seus sistemas digitais que, ao contrário do esperado, em não raras vezes, são obstáculos às mudanças (o tão conhecido: “o sistema não aceita"); medo de quem é outro, levantando bandeiras que já faziam parte do museu da história (ressurge a tradição, a família e a propriedade); a padronização dos estilos de escrita, fruto de uma crescente burocratização, para serem legitimados, fragmentam os textos encarnados. Isso, e muito mais, o que nos impõem ao pensar a escola, o currículo e as políticas curriculares incluir, especificamente, o contexto geo-histórico nos e dos caminhos que tomou o currículo escolar tanto como estudo descritivo da realidade e prescritivo do agir assim, como sua concreta objetivação.

\section{A ESCOLA E O CURRÍCULO}

E hoje, neste contexto, temos uma onda conservadora a clamar por bases curriculares que se afastem dos discursos que inspiraram as reformas educacionais dos anos 1990, a exemplo da espanhola que, por sua vez, inspirou, ou mesmo influenciou, a brasileira expressa na LDB de 1996. Esses discursos, que não se bastam no exemplo da reforma espanhola, são representativos na e da chamada Nova Ordem Mundial que foi urdida pela “cascata de atualizações” já referida na introdução deste artigo - novas tecnologias, fim da Guerra Fria. As mudanças no mundo do trabalho, com a descentralização, a flexibilização e a globalização econômica que precisava da mão de obra do chamado terceiro mundo, entram nos currículos, não necessariamente, com a mesma argumentação; mas sempre como uma constatação do advento de uma nova ordem mundial. Ainda na primeira década desse século, Sene (2008, p. 20) nos diz que

Desde muito me parece que a escola não vem conseguindo enfrentar as novas e ampliadas demandas do mundo contemporâneo, marcado por rápidas transformações econômicas, tecnológicas, políticas e culturais. Tenho pensado sobre as consequências dessas transformações no sistema educacional, em especial no ensino médio.

Esse é um trecho, abordando a existência de "um novo mundo", da tese de doutorado, defendida na Universidade de São Paulo, As reformas educacionais após a abertura política no Brasil e na Espanha: uma análise crítica do Ensino Médio e da Geografia. A respeito desse "novo mundo" o autor argumenta que: 
[...] entre as principais justificativas para as constantes reformas educacionais predomina a necessidade de adaptação ao atual momento do capitalismo, marcado pela revolução informacional, dando origem a chamada sociedade do conhecimento. Isso está muito presente nos documentos brasileiros e espanhóis. Assim, ao que parece, as possibilidades de emancipação são muito limitadas porque a pessoa foi subsumida pelo trabalhador na formação escolar quando deveria ser o contrário. (SENE, 2008, p. 32).

Trechos abordando a existência de "um mundo novo" são recorrentes. O professor Nelson Pretto, um estudioso das tecnologias na educação, na $52^{\circ}$ reunião anual da Sociedade Brasileira para o Progresso da Ciência (SBPC), em 2000, aborda o tema:

A mundialização da economia, evidente em todos os recantos, tem levado, muitas vezes, a generalizações sobre o processo de globalização nem sempre coerentes com outros movimentos fora da área econômica. Percebe-se, conforme já afirmou Gianni Vattimo (1991), uma também multiplicação de valores e culturas locais, mesmo com a grande concentração de capital e de empresas no mundo da mídia. (PRETTO, 2000, s.p).

Porém, com argumentações distintas do primeiro exemplo:

O exemplo da produção educativa para a televisão já foi bastante evidente e essa dicotomia entre aqueles que sabem televisão e os chamados conteudistas tem-se mostrado completamente superada, tanto do ponto de vista teórico como prático. O momento exige que tenhamos uma maior integração entre aquelas áreas que antes eram chamadas apenas de áreas meios com aquelas chamadas de áreas de conteúdo. Instala-se assim, obrigatoriamente, um processo de negociação permanente entre as mais diversas áreas, com especial ênfase à Internet, e à toda uma formação da comunidade escolar (estudantes, professores, direção, comunidade vizinha) para o uso pleno das tecnologias. (PRETTO, 2000, s.p).

São esses, apenas dois exemplos entre a propulsão de discursos, de constatações e posicionamentos em relação à nova ordem mundial. Uma mesma constatação histórica, o mundo havia sofrido política, ideológica e tecnologicamente uma ruptura visivelmente inegável. Momento de aceleração, como explicado, teoricamente, por Milton Santos (1994, p. 15):

Acelerações são momentos culminantes da história, como se abrigassem forças concentradas explodindo para criar o novo. A marca do tempo, de que falava Michelet, no prefácio de sua história do Século XIX, é marcada por essas grandes perturbações aparentemente sem sentido. Daí a cada época, malgrado a certeza que se atingiu um patamar definitivo, as reações de admiração ou de medo, diante do inusitado e a dificuldade para entender novos esquemas e para encontrar um novo sistema de conceitos que expressem a nova ordem em gestação.

Momento de aceleração, cuja interpretação induziu a constituição de uma profusão de narrativas. Na grande maioria delas, a díade defenestrada naquele momento - direita e esquerda não estava declarada, mas era perceptível. Muitas dessas narrativas se pautavam nas críticas aos currículos oficiais únicos, muito deles embalados pelo referencial crítico do currículo, tão 
cuidadosamente urdido desde os reconceitualistas e pela Nova Sociologia da Educação dos anos 1970, quando se indicava também uma revisita às teorias sociais críticas.

E defendemos que, apesar da diferença de posições que variavam das mais radicais às mais tímidas e saudosistas, praticamente, todas compactuavam com o espírito do tempo presente e tinham uma verve de inovação. A apontar essa inovação tem-se a criação de termos com prefixos anunciativos de ruptura: neoliberalismo, pós-crítica, pós-modernidade assim como pósestruturalismo e pós-fundacional. A pedagogia tornava-se adjetivada:

A pedagogia pós-moderna tem que focar nas inconstantes atitudes, representações e desejos desta nova geração que é forjada pela atual conjuntura histórica, econômica e cultural. Por exemplo, as condições de identidade e a produção de novos mapas de sentido devem ser entendidas dentro de novas práticas culturais híbridas inscritas em relações de poder que entrecruzam diferentemente raça, classe, gênero e orientação sexual. Mas tais diferenças não devem apenas ser entendidas em termos do contexto de cada luta, mas também por uma linguagem comum de resistência que aponte para um projeto de esperança e possibilidades. Nisto é que reside a importância do legado positivo do modernismo crítico: faz-nos lembrar da importância da vida pública, da luta democrática e dos imperativos de liberdade, igualdade e justiça. (GIROUX, 2009, p. 123).

Então, teríamos frentes antagônicas, mas hegemonicamente não conservadoras. Até que no século XXI é protagonizada uma avaliação generalizada e generalizante que atravessa tanto as narrativas do senso comum, como aquelas mais intelectualizadas, sem dúvida, fruto de constatações que vêm sendo disseminadas socialmente do Oiapoque ao Chu^ ${ }^{4}$ de que "tudo o que fizemos deu errado": ninguém aprende mais nada, ninguém mais sabe ler. É como se durante todo o longo período de crítica hegemônica à Escola Tradicional e de defesa a processos de ensino e aprendizado mais "significativos", houvesse ocorrido, não uma sólida ruptura, mas apenas a hibernação de alguns padrões que ressurgem muito fortes na busca de causas para o descalabro que teria se tornado a Educação no país: é o construtivismo, é o Banco Mundial, são os comunistas, é não ensinar a tabuada ${ }^{5}$, é achar que experiência é conhecimento, é a deslegitimação da ciência, é o professor sem autoridade; enfim, é um dizer "antigamente não era assim”.

Construindo uma flecha do tempo do campo curricular, concluiríamos que, após estudos com proposições de currículos distanciados de padrões essencialistas, fechados, universalistas e cientificistas, como por exemplo, o currículo rizomático (GALLO, 1995 inspirado em DELEUZE e

\footnotetext{
${ }^{4}$ Expressão que se utilizando dos pontos extremos, norte e sul, do território brasileiro expressa algo que abrange todo o país.

${ }^{5}$ É bastante conhecida a crítica que se faz ao modo mecânico com que a Tabuada - tábua das quatros operações fundamentais entre os números de um a dez - foi/é ensinada nas escolas brasileiras.
} 
GUATTARI, 1995), o a-com-tecer do currículo (CARVALHO, 2008 inspirada em FELLIPE SERPA, 2004), temos um revés fruto de um mundo refém da insegurança surgida da violência, ou do que pode ser representado como violência, que sempre se instaura quando ocorre alguma alteração nos jogos de poder, em momentos pós-ruptura.

Um cenário de "pós-queda do Muro", outro de "pós-queda das Torres Gêmeas"; e uma propulsão de narrativas curriculares.

Para objetivar esse discurso teórico, ficaremos com três exemplos, bastante ilustrativos, desse revés conservador: um de dimensão teórica, o Conhecimento Poderoso defendido, entre outros, pelo britânico Michel Young; e dois, de eventos específicos: um brasileiro, a tentativa de retorno ao método fônico de alfabetização na prefeitura municipal de Salvador-Bahia, e outro português, um olhar sobre o Processo de Bolonha em Portugal, o exemplo da Universidade do Minho na cidade de Braga.

\section{O CONHECIMENTO PODEROSO}

Michel Young é conhecido mentor da chamada Nova Sociologia da Educação, que desde os anos 1970, assim como várias outras correntes progressistas pedagógicas, perseguem ou perseguiam uma escola mais próxima ao que se convencionou chamar "realidade do aluno". Partia-se de uma crítica ao iluminismo, ao conteudismo presente nos currículos, ao caráter cientificista da escola, que considerava a ciência como único conhecimento legítimo e com isso tomava o conhecimento como instrumento de controle e poder. Pode-se interpretar que tínhamos uma oposição entre essencialismo-existencialismo.

Em 2007, em uma revisita crítica radical à Nova Sociologia da Educação, Young publica Para que servem as escolas? Esta indagação que se tornou parte central de seu discurso há mais de uma década é um dilema comum a todos que se debruçam a pensar a Educação. Quando, em 2007, lemos o texto, também nos fizemos essa pergunta. E ao longo dessa década, frente ao que vislumbramos como, quiçá aparente, perda da qualidade das escolas, emerge, nos mais variados contextos, diversas indagações tais como: o que teria a escola perdido nos últimos tempos? O que fizemos com nossos conteúdos?

É nas respostas dadas que Young, ao longo desse tempo, cada vez mais, aproxima-se de um discurso essencialista, começando por considerar uma revisita aos ensinamentos do Iluminismo com vistas a possíveis atualizações (YOUNG, 2010); depois, chegando a defender a existência de um conhecimento pré-existente que a escola teria que resgatar, com a alegação de que "o 
conhecimento curricular - ou disciplinar - é independente do contexto, diferentemente do conhecimento baseado na experiência que os alunos trazem para a escola". (YOUNG, 2016, p. 34). Haveria um "medo do conhecimento", entendido como o conhecimento científico que deverá ser vencido para se atingir nas escolas o Conhecimento Poderoso. Há uma negação dos contextos. Em recente artigo afirma: "[...] tratavam os critérios de conhecimento como se fossem flexíveis". (YOUNG, 2016, p. 27). Considerar que os Conhecimentos não são flexíveis é desconsiderar qualquer atenção ao contexto de produção e/ou existência dos conhecimentos. É uma defesa arraigada de bases sólidas e fortes fundamentos. Para tal, questiona o amplo leque de autores não diretamente ligados à educação que auxiliam na composição do campo curricular.

Dois outros aspectos merecem ser mencionados sobre o 'medo do' ou o 'ataque ao' conhecimento. Em primeiro lugar - e amplamente ignoradas fora do âmbito das ciências sociais e das humanidades -, as tradições filosóficas que se desenvolveram a partir de Nietzsche, Heidegger e Wittgenstein, levando aos pós-modernistas de hoje, tais como Rorty, Lyotard e Foucault, que fizeram da crítica à tradição ocidental do conhecimento um projeto intelectual. Isso significa que, ironicamente, os educadores e os cientistas sociais anticonhecimento podem apelar à Filosofia para a construção de uma perspectiva contrária ao conhecimento e como um suporte para os seus argumentos anticonhecimento. Esses filósofos, frequentemente, não escrevem sobre educação - embora o livro de Foucault, Vigiar e punir, bem como Ideologia e aparelhos ideológicos do Estado, de Louis Althusser, tenham tido uma poderosa, porém perniciosa, influência nos estudos educacionais. (YOUNG, 2016, p. 29).

É a negação de toda uma proposição contemporânea sobre currículo que, ironicamente, foi ajudada a construir pelo próprio autor. Tempos conservadores. Young vem sendo impetuoso na defesa do Conhecimento Poderoso. Esteve recentemente no Brasil, chamado pela Fundação Lemmann, para participação na comissão da BNCC, a Base Curricular Nacional em processo de implantação no território brasileiro, ${ }^{6}$ quando reafirmou sua posição.

\section{UMA TENTATIVA DE RETORNO AO MÉTODO FÔNICO DE ALFABETIZAÇÃO}

$\mathrm{Na}$ crítica à chamada escola tradicional é fundamental a constatação da "falta de sentido da escola". Falta de sentido que pode ser observada no processo de alfabetização e que deságua na crítica aos métodos fonéticos. Na defesa de que alfabetizar é mais que uma decifração de códigos, ganha fôlego a questão do letramento, a Psicogênese da língua escrita de Emília Ferreiro que compactuam com a famosa máxima de Paulo Freire: a leitura do mundo antecede a leitura da

\footnotetext{
${ }^{6}$ Dois endereços para maior elucidação dessa discussão:

1. Site oficial da BNCC: http://basenacionalcomum.mec.gov.br/\#/site/conheca

2. Palestra do Prof. Young no Seminário sobre BNCC: https://www.youtube.com/watch?v=Q9ZH4AcW0y0
} 
palavra. No cotidiano escolar abandona-se o descontextualizado Ivo viu a Uva e as famílias de sílabas que são substituídos pelo aprendizado da escrita do próprio nome e de nomes familiares - de colegas, por exemplo -, de pequenos textos cotidianos; tudo para facilitar a atribuição de sentidos durante o processo de alfabetização. Tudo é texto, lê-se, portanto, o mundo. ${ }^{7}$

Depois de um tempo das críticas ao Ivo viu a Uva e ao concreto afastamento dessas práticas do cotidiano escolar brasileiro, é natural que se coloque a questão: o que foi feito de nossa alfabetização? Mas, o que poderia/deveria ser uma atualização de caminhos torna-se confronto com a volta de defesa do método fonético.

Em Salvador, no início de uma gestão municipal, em 2013, durante a Jornada Pedagógica destinada ao planejamento de início do ano letivo, os professores foram surpreendidos com a informação de que a Prefeitura havia firmado parceria com o sistema de ensino do Instituto Alfa e Beto (IAB). Pretendia-se, com isso, introduzir a alfabetização com o método fonético, escolha metodológica anunciada desde o nome da instituição, Alfa e Beto. Não era uma discussão entre métodos, mas uma imposição e, como tal, antidemocrática.

A impressa local, através do Jornal Correio da Bahia, esclareceu,

O contrato entre a secretaria e o IAB refere-se à aquisição de 3.781 kits, com material de apoio pedagógico dos programas 'Alfabetização', 'Séries Iniciais Ensino Estruturado' e 'Prova Brasil', material de apoio gerencial e logístico para a secretaria, projeto de capacitação para professores e coordenadores pedagógicos e aplicação de avaliações bimestrais nas classes do $1^{\circ}$ ao $5^{\circ}$ ano de escolarização do ensino fundamental. $\mathrm{O}$ investimento total para adquirir o material foi de $\mathrm{R} \$ 12.330 .340$.

A justificativa para a contratação do IAB foi a necessidade de um programa pedagógico com um método definido de alfabetização, capacitação de professores, material didático para alunos e professores, além do acompanhamento gerencial para a Secretaria de Educação. (http://www.correio24horas.com.br/detalhe/salvador/noticia/mp-recomenda-suspensao-dosistema-de-ensino-alfa-e-beto-em-salvador).

Entretanto, a parceria foi amplamente rejeitada pelos professores da rede municipal de ensino. De imediato os materiais didáticos, como previsto de início, não se tornaram de utilização obrigatória e aos poucos, até com recursos judiciais, a parceria foi desfeita. ${ }^{8}$

\footnotetext{
${ }^{7}$ Não é intenção, aqui, discutir alfabetização; apenas uma síntese precária para ilustrar as compreensões sobre o atual cenário educacional quanto à alfabetização.

8 Para saber mais, ler Sistema Estruturado Alfa e Beto - um retrocesso em: http://www.uneb.br/ salvador/dedc/files/2013/04/1112.PDF. Acesso: 28 set. 2016.
} 


\section{O PROCESSO DE BOLONHA EM PORTUGAL E A UNIVERSIDADE DO MINHO}

Os anos 1990, como período de Aceleração foi rico em produção teórica. Interessa-nos, aqui, a produção no campo curricular. Recomendações de organismos multilaterais internacionais e regionais, através de relatórios, cartas e afins produzidos em encontros transnacionais e amplamente divulgados, passam a ditar, de forma mais ou menos direta, a produção de documentos oficiais, leis, diretrizes e decretos nacionais.

Um fundamental exemplo dessa produção é a estrutura de Ensino Superior de Portugal. Neste país da União Europeia o Ensino Superior é, hoje, institucionalizado via o chamado Processo de Bolonha que tem entre os seus mais "célebres objetivos" a mudança de paradigma educacional. Um processo em escala europeia que documentalmente pode assim ser sintetizado:

A 19 de junho de 1999, os Ministros responsáveis pelo Ensino Superior (ES) de vinte e nove países europeus assinaram a Declaração de Bolonha e concordaram sobre a importância da enunciação de propósitos comuns para o desenvolvimento coerente e coeso da Área Europeia de Ensino Superior (AEES). Na Declaração de Barcelona (2002), reafirmaram-se estes objetivos, reconhecendo-se a sua indispensabilidade para o alcance dos níveis de competitividade atualmente requeridos pela sociedade do conhecimento. Consagrou-se, ainda, o estabelecimento, até 2010, do Espaço Europeu de Ensino Superior e do Espaço Europeu de Investigação como os principais pilares da referida sociedade. Até à reunião de Lovaina, que decorreu em 2009, aderiram à Declaração de Bolonha mais dezoito países, perfazendo um total de quarenta e sete nacionalidades diferentes. Esta adesão indicia que o Processo de Bolonha (PB) tem tido uma grande repercussão e expansão que não se limitou apenas aos países pertencentes à União Europeia (UE). Segundo um relatório elaborado pelo Grupo de Acompanhamento do Processo de Bolonha, Portugal faz parte do conjunto dos cinco estadosmembros que estão mais avançados na concretização dos seus pressupostos e que cumpriram a maior parte dos critérios estabelecidos internacionalmente para a sua execução. (MELO, 2012, p. 16).

O site oficial da Direção Geral de Ensino Superior (DGE) do Ministério da Ciência, Tecnologia e Ensino Superior de Portugal especifica:

[...] a Declaração de Bolonha em Junho de 1999 define um conjunto de etapas e de passos a dar pelos sistemas de ensino superior europeus no sentido de construir, até ao final da presente década, um espaço europeu de ensino superior globalmente harmonizado.

A ideia base é de, salvaguardadas as especificidades nacionais, dever ser possível a um estudante de qualquer estabelecimento de ensino superior, iniciar a sua formação académica, continuar os seus estudos, concluir a sua formação superior e obter um diploma europeu reconhecido em qualquer universidade de qualquer Estado-membro. ... Em última instância, o Processo de Bolonha irá desembocar numa harmonização generalizada das estruturas educativas, que asseguram as formações superiores numa Europa de actualmente, 45 países. 
Nesse enquadramento, os sistemas de ensino superior deverão ser dotados de uma organização estrutural de base idêntica, oferecer cursos e especializações semelhantes e comparáveis em termos de conteúdos e de duração, e conferir diplomas de valor reconhecidamente equivalente tanto académica como profissionalmente.

A harmonização das estruturas do ensino superior conduzirá, por sua vez, a uma Europa da ciência e do conhecimento e, mais concretamente ainda, a um espaço comum europeu de ciência e de ensino superior, com capacidade de atracção à escala europeia e intercontinental.

(Disp.: <http://www.dges.mctes.pt/DGES/pt/Estudantes/Processo+de+Bolonha/Processo+de+ Bolonha/>. Acesso: jun. 2016) (grifos nossos).

Pode-se perceber o "espírito" de um tempo globalizado provocando a institucionalização do que era um advento instituinte. Pode-se, também, aqui, pensar no "fim da história", a homogeneização final. Em paralelo, como aqui já defendido, pode-se, ainda, deslumbrar-se uma verve inovadora mesmo amparando, o que é inegável, um discurso voltado totalmente para o mercado de trabalho.

Daí podermos afirmar que o PB (processo de Bolonha) apresenta pontos comuns com o modelo de rutura defendido pela Escola Nova para outros níveis de ensino, impulsionado a partir das obras de Rousseau, Dewey, Ferrière, Freinet, Freire e muitos outros autores. Na sua essência, ao contrário do que havia vindo a ser proposto pela Escola Tradicional, ao longo do século XIX, o centro da ação educativa passou do professor para o aluno, entendendo-se o aluno como parte integrante e ativa no processo de aprendizagem. (MELO, 2012, p. 18).

Especificamente na Universidade do Minho em seu Instituto de Educação, a formação de Professores é centrada nos Princípios de Bolonha, via Lisboa. A titulação de professores acontece nos Mestrados de natureza profissionalizante destinados a egressos do curso de licenciatura em Educação Básica (que não titula professores).

Mais uma vez, um novo "espírito do tempo" dessa feita mais conservador. Em um momento em que já se faz necessária uma avaliação crítica de todo o processo, as inovações metodológicas com maior flexibilidade curricular, maior variedade de componentes curriculares, tutoriamento não passaram de letra morta e as intenções de aumento da competitividade, da mobilidade e empregabilidade dos diplomados do ensino superior no espaço europeu apesar de cartorialmente implementadas, foram tragadas pela crise econômica que assolou a Europa, notadamente Portugal.

A esse respeito tivemos oportunidade de ouvir, em uma declaração verbal o Professor Fernando Azevedo, Diretor de Mestrado em Ensino do primeiro Ciclo do Ensino Básico e de Português e História e Geografia de Portugal no segundo Ciclo do Ensino Básico: "Bolonha hoje, em relação aos princípios metodológicos, é apenas um nome de cidade”. 


\section{AFINAL, POR QUEM OS SINOS DOBRAM?}

Este texto, valendo-se da metáfora-pergunta: por quem os sinos dobram?, fez uma revisita ao período que se estende desde a queda do Muro de Berlim aos nossos dias, perspectivando-o pelas díades direita-esquerda e inovação-conservadorismo. A intenção de fundo foi traçar um painel, pretensamente amplo, dos trilhos/desvios do currículo escolar, quer como estudo descritivo da realidade, quer como prescritivo do agir e mesmo sua concreta objetivação.

A perspectivação através de díades, uma apropriação direta do termo como utilizado por Bobbio (1995), foi uma escolha pela complexidade. Uma tentativa, difícil, de ao mesmo tempo não dicotomizar a interpretação e responder pela existência de posições.

Dois potentes símbolos de nossa história recente: a queda do Muro de Berlim - com o que trouxe simbolicamente de "novo mundo", transitando entre as, muitas vezes, antagônicas posições neoliberais (capitalistas) e democráticas (padrões de liberdade) - e o ataque às Torres Gêmeas com o que trouxe simbolicamente de "mundo amedrontado", caminhando a passos largos para a intolerância com o mundo que buscava a pluralidade -, direcionaram a cartografia desta revisita.

Recente cartum apógrafo difundido pelas redes sociais mostra uma Berlim ainda comemorando barulhentamente a queda do Muro enquanto já se construía um outro muro em torno da Europa.

Bela metáfora que trazemos aqui para o campo do currículo. Ainda discutíamos transitando entre princípios mais à esquerda, por exemplo, por uma escola acolhedora da diversidade e mais à direita, por exemplo, por uma escola voltada ao mundo do mercado, mas contemporânea - propondo, cada um a seu modo currículos abertos, contra uma educação bancária, sem grades curriculares cerceadoras, quando nos vimos frente ao retorno de cerceamentos nos âmbitos dos conteúdos programáticos e valores de tempos atrás.

Diferenças não pensadas como díades, mas como profundos antagonismos. Como se diferentes modelos não tivessem interseções. Nesse sentido, temos a volta de uma ordem discursiva de defesas de neutralidade, verdade absoluta, padrões fixos que se pronunciam claramente contra os estudos que perseguem, sobretudo, concepções e noções menos finalistas e totalizantes.

Vemo-nos mais distante da “ontologia fraca” proposta por Vattimo (1996, p.190):

Nesta situação, deve-se falar, na minha opinião, de uma 'ontologia fraca' como única possibilidade de sair da metafísica - pelo caminho de uma aceitação - convalescença-distorção que não tem nada do ultrapassamento crítico característico da modernidade. Pode ser que nisso resida, para o pensamento pós-moderno, a chance de um novo, fracamente novo, começo. 
Trazemos, portanto, a discussão que o "espírito do tempo" do mundo no qual vivemos é notoriamente conservador, advindo de profunda crise - política, ideológica, econômica - e pode ser explicado em duas dimensões - de um lado, pelo essencialismo, que leva a dicotomia; de outro pelo desejo de manutenção de um cenário, tradicionalmente, socialmente desigual, que vinha dando sinais de que estava se exaurindo.

Quanto ao essencialismo, este nos impele a uma eterna busca da verdade. Neste tipo de busca não há, a não ser muito superficialmente, revisões e/ou atualizações, mas descartes. Sendo assim, pensar a crise acaba sendo, de certa maneira, algo saudosista, nostalgia de um passado que pode nem ter existido. Se o novo não deu certo, volta-se ao que tínhamos antes, refletido na expressão: "era feliz e não sabia".

Quanto às tentativas de manutenção de um mundo existente, a história da humanidade é uma história de resistência à perda de regalias. É por essa resistência que a díade direita-esquerda, como propõe Bobbio (1995), fundada no desejo da esquerda pela igualdade, estará sempre presente.

Pressentimos que apesar de não faltar motivos para uma nova inflexão de rumo, os sinos insistem em dobrar. Enquanto produzíamos este texto, o governo brasileiro lançou uma Medida Provisória decretando um novo Ensino Médio ${ }^{9}$ para o país. Independente do conteúdo, mudanças educacionais por Medida Provisória indicam períodos de não inovação; portanto, conservadores e de não busca pela igualdade. Os sinos, como sempre, dobram por nós. Os rintocchi de morte dessa vez são réquiens para a Democracia.

\footnotetext{
${ }^{9}$ Para saber mais, acessar http://portal.mec.gov.br/component/content/article?id=39621
} 


\section{REFERÊNCIAS}

ABBAgnAnO, Nicola. Dicionário de Filosofia. Trad.: Alfredo Bosi. São Paulo: Mestre Jou, 1982.

BOBBIO, Noberto. Direita e Esquerda - razões e significados de uma distinção política. 2. reimp. Trad.: Marcos Aurélio Nogueira. São Paulo: Editora da Universidade Estadual Paulista. 1995.

CARVALHO, Maria Inez. O a-com-tecer de uma formação. Revista da FAEEBA-Educação e Contemporaneidade, Salvador, v. 17, n. 29 , , p. 159-168, jan./jun. 2008.

Uma viagem pelos espaços educacionais do Município de Santo Antônio de Jesus: possibilidades, atualizações, singularidades e transituações. Tese (Doutorado em Educação) - Faculdade de Educação, Universidade Federal da Bahia. Salvador, 2001.

; SARDELICH, Maria Emília. O que vamos guardar de nós? São Paulo: Grupo Editorial Cone Sul, 2000.

CASTELLS, Manuel. A sociedade em rede. São Paulo: Paz e Terra, 1999.

DELEUZE, Gilles; GUATTARI, Felix. Mil Platôs: capitalismo e esquizofrenia. Trad.: Aurélio Guerra; Célia Pinto Costa. Rio de Janeiro: Ed. 34, 1995. v. 1. (Coleção Trans).

DIAS, Helder. Os sinos que unem John Donne, Hemingway e Raul Seixas. In: Revista Bula, 2016. Disp.: <http://www.revistabula.com/1553-os-sinos-que-unem-john-donne-hemingway-e-raul-seixas/>. Acesso set. 2016.

FUKUYAMA, F. O fim da História e o último homem. Rio de Janeiro: Rocco, 1992.

GALlO, Sílvio. Conhecimento, transversalidade e currículo. ANPED. Anais da $8^{\text {a }}$ Reunião Anual... [s.1, s.n], 1995. Digitado.

GIROUX, H. Deixando pra lá: juventude fronteiriça e educação pós-moderna. Revista FACED, Salvador, n.16, p.103130, jul./dez. 2009.

HARVEY, David. Condição pós-moderna: uma pesquisa sobre as origens da mudança cultural. Trad.: Adail Ubirajara Sobral; Maria Stela Gonçalves. São Paulo: Edições Loyola, 1993.

HEMINGWAY, Ernest. Por quem os sinos dobram? Trad.: Luís Peazê. Rio de Janeiro: Bertrand Brasil, 2013. Edição Kindle.

LÉVY, Pierre. O que é o virtual? 2. ed. São Paulo: Ed. 34, 2003. (Coleção Trans).

MELO, Ana Luísa P. Souto. O Impacto do Processo de Bolonha na Formação de Professores de Educação Visual e Tecnológica. Portugal: Universidade da Beira Interior Ciências Sociais e Humanas, 2012. Disp.: <https://ubibliorum.ubi.pt/bitstream/10400.6/2592/1/TeseALSM(FINAL).pdf>. Acesso set. 2016.

PRETTO, Nelson. Desafios da educação na sociedade do conhecimento. SBPC. Anais da 52 ${ }^{\mathbf{a}}$ Reunião Anual... Brasília, 2000. Dtsp.: <http://www2.ufba.br/ pretto/textos/sbpc2000.htm>. Acesso: set. 2016.

SANTOS, Milton. A aceleração contemporânea: tempo mundo e espaço mundo. In: Fim de século e globalização. 2. ed. São Paulo: Hucitec, 1994.

SENE, J. E. As reformas educacionais após a abertura política no Brasil e na Espanha: uma análise crítica do Ensino Médio e da Geografia. Tese (Doutorado em Educação) - Universidade de São Paulo. São Paulo, 2008.

SERPA, Luiz Felippe. Rascunho digital: diálogos com Felippe Serpa. Salvador: EDUFBA, 2004.

VATTIMO, Gianni. O fim da modernidade. São Paulo: Martins Fontes, 1996.

YOUNG, M. Para quem servem as escolas? Educação e Sociedade, Campinas, vol. 28, n. 101, p. 1287-1302, set./dez. 2007.

Os estudos do currículo e o problema do conhecimento: atualizar o Iluminismo? In: SÁ, M.R.G.B.; FARTES,

V.L.B. (Orgs). Currículo, Formação e Saberes profissionais: a (re)valorização epistemológica da experiência. Salvador: EDUFBA, 2010. p. 19-36.

Por que o conhecimento é importante para as escolas do século XXI? Cadernos de Pesquisa Fundação Carlos Chagas, Rio de Janeiro, v. 46, n. 159, p.18-37, jan.-mar. 2016. 


\section{RESUMO}

Discute-se neste texto - a partir da pergunta alusiva ao romance de Ernest Hemingway Por quem os sinos dobram? -, a emergência de um atual espírito do tempo conservador que sucede tempo de anúncios de inovação e as ressonâncias dessa emergência nas narrativas curriculares. Tendo como recorte temporal o final do século XX com a queda do Muro de Berlim em 1989 e o início do século XXI com o ataque às Torres Gêmeas nos Estados Unidos em 2001, interpreta-se a constituição de narrativas curriculares a partir de díades discursivas como direita-esquerda com inspiração em Norberto Bobbio (1995) e seu rintocchi de morte. Anunciando tensões entre compreensões diferentes de mundo, questões curriculares atuais são discutidas para exemplificar uma identificada volta de ordens discursivas finalistas e totalizantes, em nome de inovações curriculares. Conclui-se que, como sempre, os sinos continuam a dobrar e que é preciso que estejamos alerta aos réquiens que, atualmente, ameaçam a nossa Democracia.

Palavras-chave: Narrativas Curriculares. Escola. Antagonismos. Conservadorismo.

\section{LAS CAMPANAS TOCAN POR NOSOTROS. EL MUNDO, EL BRASIL E LAS NARRATIVAS CURRICULARES DE LOS ULTIMOS TIEMPOS}

\section{RESUMEN}

Se argumenta en este texto - a partir de la pregunta en alusión a la novela de Ernest Hemingway Por quién doblan las campanas? - la aparición de un espíritu de tiempo conservador que sucede anuncios de innovación y las resonancias en las narrativas del curriculum. Con el marco de tiempo al final del siglo XX con la caída del muro de Berlín en 1989 y principios del siglo XXI con el ataque a las torres gemelas en los Estados Unidos en 2001, se interpreta la constitución de las narrativas del curriculum de las diadas discursivas como derechaizquierda con la inspiración en Norberto Bobbio (1995) y su muerte rintocchi. Al anunciar las tensiones entre diferentes concepciones del mundo, se discuten cuestiones curriculares actuales para ejemplificar discursos finalistas y totalizadores que regresan en nombre de las innovaciones curriculares. La conclusión es que, como siempre, las campanas aún resuenan y que debemos estar alerta a requiems que amenazan actualmente nuestra democracia.

Palabras Claves: Narrativas del plan de estudios. Escuela. Antagonismos. Conservatismo

\section{THE BELLS TOLL FOR US. THE WORLD, BRAZIL AND CURRICULUM NARRATIVES OF RECENT YEARS}

\section{ABSTRACT}

It is discussed in this text - from the question alluding to the novel by Ernest Hemingway For Whom the Bell Tolls - the emergence of a current spirit of conservative time that succeeds an innovation time, and the resonances of this emergence in the curriculum narratives. Having the end of the twentieth century with the fall of the Berlin Wall in 1989 and the early twenty-first century with the attack on the Twin Towers in the United States in 2001 as the time frame, the constitution of curriculum narratives are interpreted from discursive dyads as right-left with inspiration in Norberto Bobbio (1995) and his rintocchi of death. Announcing tensions between different understandings of world, current curricular issues are discussed to illustrate an identified return of discursive orders finalists and totalizing, on behalf of curricular innovations. We conclude that, as always, the bells continue to toll and that we must be alert to the requiems that currently threaten our democracy.

Keyword: Currriculum Narratives. Scholl. Antagonisms. Conservatism.

Submetido em Set./2016

Aprovado em Dez./2016 